\title{
CAPTURANDO OS ANOS: A REPRESENTAÇÃO DA VELHICE NOS PROJETOS DE ARIANNE CLÉMENT
}

\author{
Capturing the time: the representation of old age in the projects of Arianne Clément
}

\author{
Victor André Pinheiro Cantuário \\ http://orcid.org/0000-0002-1706-1016 (1) \\ Universidade Federal do Amapá, Campus Santana, Santana, \\ AP, Brasil. 68925-000 - pedagogia.santana@unifap.br
}

Resumo: O artigo tem por objetivo demonstrar como a velhice é representada nos projetos de Arianne Clément. Para tanto, utilizou-se o acervo composto por três álbuns de imagens disponíveis no sítio oficial da fotógrafa canadense, além dos apontamentos de Sontag (2005) e Flusser (2006) sobre a arte da fotografia. Tais aportes teóricos foram fundamentais para que se compreendesse a representação da velhice por Clément como uma busca por um belo que se afasta de uma ideia comum associando-o à juventude, como se somente fosse belo aquilo que aparenta ser jovem. Clément, por outro lado, não apenas se dedica a dar visibilidade a idosos acima dos 70 anos como expõe o que suas vozes dizem sobre sexualidade, longevidade, feminismo e beleza. Dessa forma, conclui-se que Clément é artista comprometida com uma leitura da velhice que desafia visões desta segundo as quais deve permanecer confinada ao silêncio e ofuscada por uma miríade imagética que artificializa as experiências da vida e tenciona apagar da paisagem humana qualquer manifestação da velhice porque isto sinalizaria para a visualização do declínio do próprio ser.

Palavras-chave: Velhice. Arianne Clément. Fotografia.

Abstract: The paper presents the old age in the projects of Arianne Clément using the images available in her website as well as the considerations of Sontag (2005) and Flusser (2006) important to the understanding of the art of photography and through this to the comprehension of Clément's representation of old age as a searching for a non commom beauty, that is, the Canadian photographer challenges a trivial meaning of beauty linked solely to the youth, to what seems eternally young. Clément, on the other hand, shines a light on the elderly from 70 years old on and on their questions about sexuality, longevity, feminism, and beauty. For this, Clement is an artist committed to a reader of old age that wants to take it out of the shadows and undo visions of it according to which it is the age of decline of all beings.

Keywords: Old Age. Arianne Clément. Photography.

\section{Palavras iniciais}

No comunicado de 11 de março de 2020, quando declarou que a COVID-19 deveria ser caracterizada como uma pandemia, a Organização Mundial da Saúde (OMS) ressaltou, a partir de dados disponíveis até aquele momento, que as pessoas com maior risco de serem infectadas pelo coronavírus seriam os idosos (acima de 60 anos) e aqueles com quadros médicos específicos, acometidos por doenças cardiovasculares, diabetes, câncer, problemas respiratórios crônicos, por exemplo (WORLD HEALTH ORGANIZATION, 2020, n.p). 
Essa declaração, se por um lado serviu de alerta para que se dirigisse um olhar diferenciado aos citados grupos de risco, por outro, algumas vozes políticas dissonantes a utilizaram como justificativa para que se desenhassem medidas de isolamento voltadas apenas às potenciais vítimas do vírus, contando, inclusive, com algum apoio popular, apesar de a própria OMS, no mesmo comunicado, haver esclarecido tanto sobre a gravidade da doença quanto sobre o fato de que qualquer pessoa poderia ser infectada.

Eis a velhice de volta à cena, mas vista de diferentes perspectivas: reforçando-se as fragilidades da idade e das condições socioeconômicas, a força da vida e a vontade de se viver, permitindo-se pensar nos que partiram antes de serem alcançados por ela, dotandoa de uma subjetividade particular, nas lições dos filósofos que escreveram a respeito desse momento da existência humana, nas dezenas de filmes, animações e músicas que a investigaram e questionaram, nos procedimentos e tratamentos estéticos que prometem retardá-la, nos avanços da medicina e campos científicos correlatos que se ocupam de tratá-la.

Mas se a velhice apresenta possibilidades de leituras e interpretações, não deixa de despertar o olhar interessado de quem se fascina por ela e quer capturá-la em suas lentes a fim de guardar o momento em suas configurações mais sensíveis e por isso singulares. Esse é o caso de Arianne Clément.

Desenvolvendo projetos cujo público é integrado por idosos, ao longo de vários anos de exercício profissional, a fotógrafa canadense vem propondo, pelo seu trabalho, reflexões sobre o processo de envelhecimento, buscando retratar o que os fotografados têm a dizer através de suas imagens, querendo captar não somente o inevitável que o caminho rumo ao envelhecimento contém, mas também a beleza presente nos encontros, nas histórias de vida e nos sorrisos, seguindo de perto a afirmação de Sontag (2005) segundo a qual o fotógrafo, às vezes, quer espelhar a realidade e é, no fim das contas, a arte em questão uma tentativa de traduzir estados de coisas, eventos, para a forma de objetos, as fotografias, segundo disserta Flusser (2006).

Nos registros visuais em preto e branco, Clément demonstra, assim se entende, estar preocupada em operar um retorno aos princípios da fotografia, quando o produto resultante do ato de fotografar era objeto em preto e branco, mas, ao mesmo tempo, expressa a vontade de ler a velhice aplicando esse estilo em particular, como se pela negação de uma certa configuração de cores também negasse a excessiva artificialização que elas parecem conter.

Caminhando por essa linha de pensamento, o artigo quer expor o olhar de Clément sobre a velhice nos três projetos que realizou em torno do tema, trazendo fotografias de cada um desses enquanto se tece uma via de problematização da arte da fotografia com o auxílio das considerações sobre esta extraídas dos dois autores há pouco citados como referências. 


\section{A passagem do tempo nas lentes de Clément: lendo a velhice nos olhos dos outros}

Em uma das primeiras cenas de Fatal, adaptação de The Dying Animal do escritor norte-americano Philip Roth, publicado originalmente em 2001, o protagonista, David Kepesh, posicionado na janela de seu apartamento, observando a chuva, reflete sobre o ato de envelhecer, considerando a diferença entre os sinais do tempo no corpo humano e a percepção mental e dando a entender que se se trata de um fenômeno biológico, nem todos estão dispostos a aceitá-lo (ELEGY, 2008, n.p).

Esse entendimento negativo do envelhecimento como decadência, perda e lamento, explorado ao longo do filme, como se a velhice roubasse a suposta beleza que pertenceria unicamente à juventude e fosse uma maldição, é contrastado por outras perspectivas que, na contramão, querem ver o que há nesse fenômeno além de uma comum representação visual da passagem do tempo.

Inscrita nessa segunda linha de pensamento, Arianne Clément, canadense de 39 anos, vem desenvolvendo projetos por meio dos quais realiza viagens para todos os continentes, envolvendo-se em ações humanitárias que tenham por objeto os marginalizados, seus sujeitos preferidos, segundo ela mesma o expressa.

Um dos grupos que tem lhe despertado interesse nos últimos anos é o dos mais velhos e estes são tema de três projetos que podem ser visualizados no seu sítio oficial: How to live to 100? (Comment vivre 100 ans), The Art of Aging (L'Art de Vieillir) e 100 years old, age of beauty (100 ans, âge de beauté).

O primeiro teve por intenção a realização de viagens às chamadas Blue Zones ${ }^{1}$, assim denominadas no ano de 2005 pela revista National Geographic, que seriam cinco áreas nas quais a expectativa de vida e o número de habitantes com 100 anos ou mais são superiores ao do restante do mundo (BUETTNER, 2020, n.p).

Os outros dois projetos mantêm os olhos sobre o mesmo tema e públicos, mas ao passo que o segundo explora os corpos, a sexualidade e a beleza para além de um ideal estético vinculado a uma idade específica, vendo nos idosos acima de 70 anos como essas questões se manifestam, o último concentra a atenção em 10 centenárias da região de Montérégie, em Quebec, e mostra seus esforços para se manterem, se sentirem e parecem bem, e, enquanto são fotografadas, Arianne as propõe questionamentos sobre "[...] juventude, velhice, feminismo, sexualidade, charme, aparência, amor etc."2 (CLÉMENT, 2020, n.p, tradução minha).

As informações disponibilizadas nos relatos daqueles fotografados evidenciam como, distante do pessimismo de Kepesh e de outros, cada um compreendeu que a passagem do tempo não precisa estar associada à decrepitude ou à demência, pois se envelhecer é a

\footnotetext{
1 São as seguintes: província de Ogliastra, na Sardenha - Itália; Península de Nicoya - Costa Rica; a comunidade Loma Linda, na Califórnia - Estados Unidos; o arquipélago de Okinawa - Japão; a ilha de Ikaria - Grécia. Dan Buettner, associado à National Geographic e fundador do Projeto Zonas Azuis, escreveu um livro, publicado em 2019, e mantém um sítio discutindo o assunto.

2 "[...] about youth, old age, feminism, sexuality, charm, appearance, love, etc." (CLÉMENT, 2020, n.p)
} 
via naturalmente seguida por todas as formas de vida orgânicas, importa buscar alcançar esse estágio consciente dos desafios a serem enfrentados e das novas perspectivas a serem vivenciadas.

Tendo em vista que com abundância nas culturas ocidentais as clínicas, os tratamentos estéticos e os cosmétidos compõem uma verdadeira indústria de combate ao envelhecimento, pois isto é tudo que milhares de pessoas não querem, ao menos não na aparência, a inevitável trilha da existência segue seu rumo propondo lições a serem aprendidas ou reaprendidas, bem como a serem ensinadas.

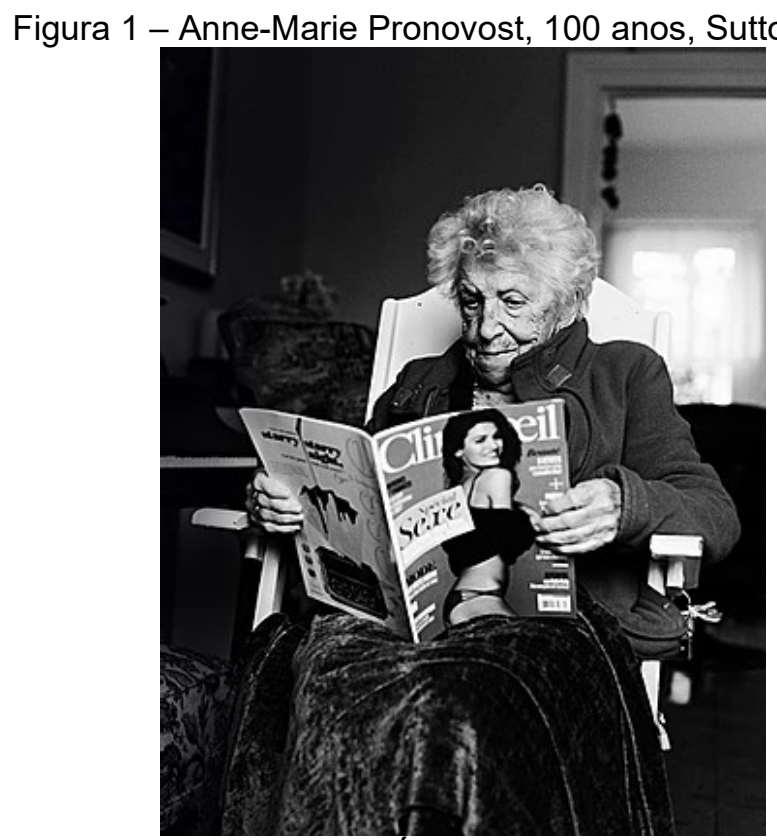

Fonte: (CLEMENT, 2020, n.p).

Apreender o mundo pela fotografia é experiência que se pode assemelhar àquela do personagem que contempla as coisas como são e não mais as sombras da caverna no mito platônico, pois pela arte da fotografia cada sujeito é exposto a um novo universo de imagens, inaugurando-se o direito do que é válido ou não de se observar e uma nova ética do ver, por isso "[...] o mais grandioso resultado da empresa fotográfica é nos dar o entendimento de que podemos guardar o mundo inteiro nas nossas cabeças - como uma antologia de imagens"3 ${ }^{3}$ afirma Sontag (2005, p. 1, , tradução minha).

Essa ideia de ver as coisas como são e não como deveriam ser se corrobora na opinião de uma das personagens do terceiro projeto (figura 1), para a qual "nós somos quem somos e isso é tudo que importa"4 (CLÉMENT, 2020, n.p, tradução minha).

Jeannette Ballard, outra das centenárias, comentou que, apesar de não se sentir mais bonita, gozava a vida olhando para o futuro "[...] mesmo que seja mais curto quando você

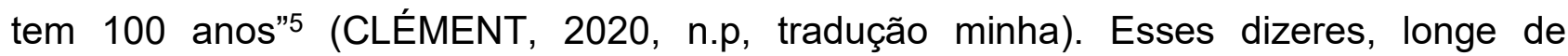

\footnotetext{
3 "[...] the most grandiose result of the photographic enterprise is to give us the sense that we can hold the whole world in our heads - as an anthology of images." (SONTAG, 2005, p. 1).

4 "We are who we are, and that's all that matters." (CLÉMENT, 2020, n.p).

5 "[...] even if it's a short one when you're 100 years old." (CLÉMENT, 2020, n.p).
} 
transparecerem angústia, expressam com sensatez uma sóbria aceitação da velhice porque não querem maquiar o real, mas expô-lo em suas minúcias.

Se é possível concluir que em uma coleção de fotografias cabe um mundo, Clément, com suas três coleções de mundos, contribui para a perpetuação de biografias que, sem o seu trabalho, provavelmente se perderiam no anonimato das multidões sem rosto, utilizando suas lentes para se apropriar de realidades que, pelas características da arte da fotografia, adquirem novos contornos, novas dimensões e são depositadas em um novo contexto de mundo, passando a manter novas relações de sentido e significado com o que as circunda.

Essas realidades a que se faz menção passam não unicamente a existir pela força da fotografia, que prova a existência de algo e de alguém ou permite se comprovar que algo aconteceu, de acordo com Sontag (2005), mas também despertam a surpresa e o espanto, preenchendo os olhos do espectador pela sua capacidade de maravilhamento com a crueza e o encanto guardados na imagem.

Figura 2 - Marie-Berthe Paquette, 102 anos, Montreal, 2016.

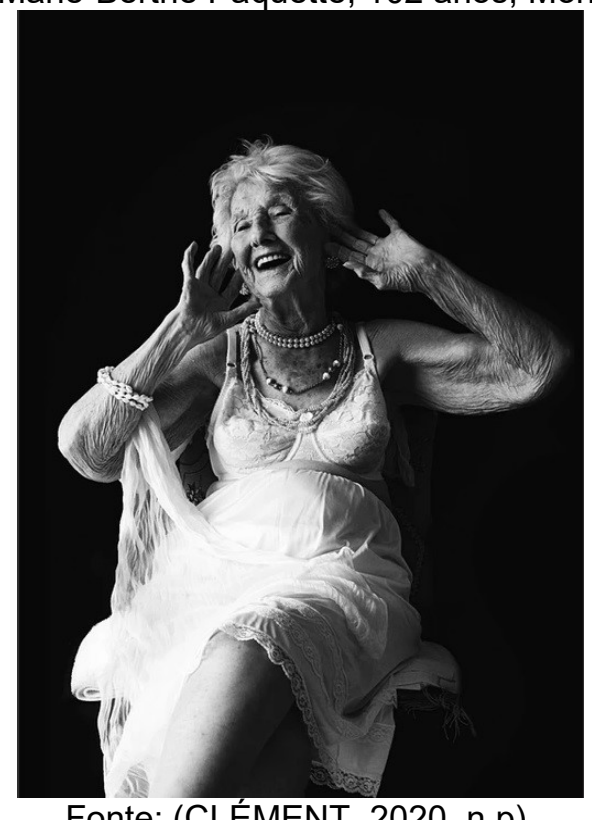

A opção de Clément por fotos em preto e branco para coletar e representar distintas percepções da velhice, um de seus temas de trabalho preferido, está relacionada, pode-se dizer, com aquilo que Flusser (2006) chama de programa, isto é, o conjunto de possibilidades oferecidas pelo aparato, a câmera, e realizado pelo operador, o fotógrafo.

Nessa esteira, o programa de um fotógrafo é a soma dos modelos, no sentido de guias de ação, que lhe servem de caminho condutor e orientam a sua prática manifesta no ato de fotografar, por isso, o fotógrafo não pode executar nenhuma ação além do que lhe permite o equipamento.

Tendo isso em mente, é bastante plausível que, além do estilo adquirido durante o seu processo de formação acadêmica, Clément tenha se profissionalizado no uso de 
equipamentos que the possibilitassem explorar um programa de fotografias em preto e branco a fim de direcionar as experiências de todos os envolvidos no processo da captação para uma linha interpretativa específica, uma linha pouco ou ainda não explorada suficientemente, a da representação visual da velhice através da fotografia, pois, sentencia Flusser (2006, p. 37, tradução minha), "[...] fotógrafos desejam produzir um estado de coisas que nunca existiu antes". ${ }^{6}$

Figura 3 - Irving Leonardo Hertlein, 90 anos, Loma Linda.

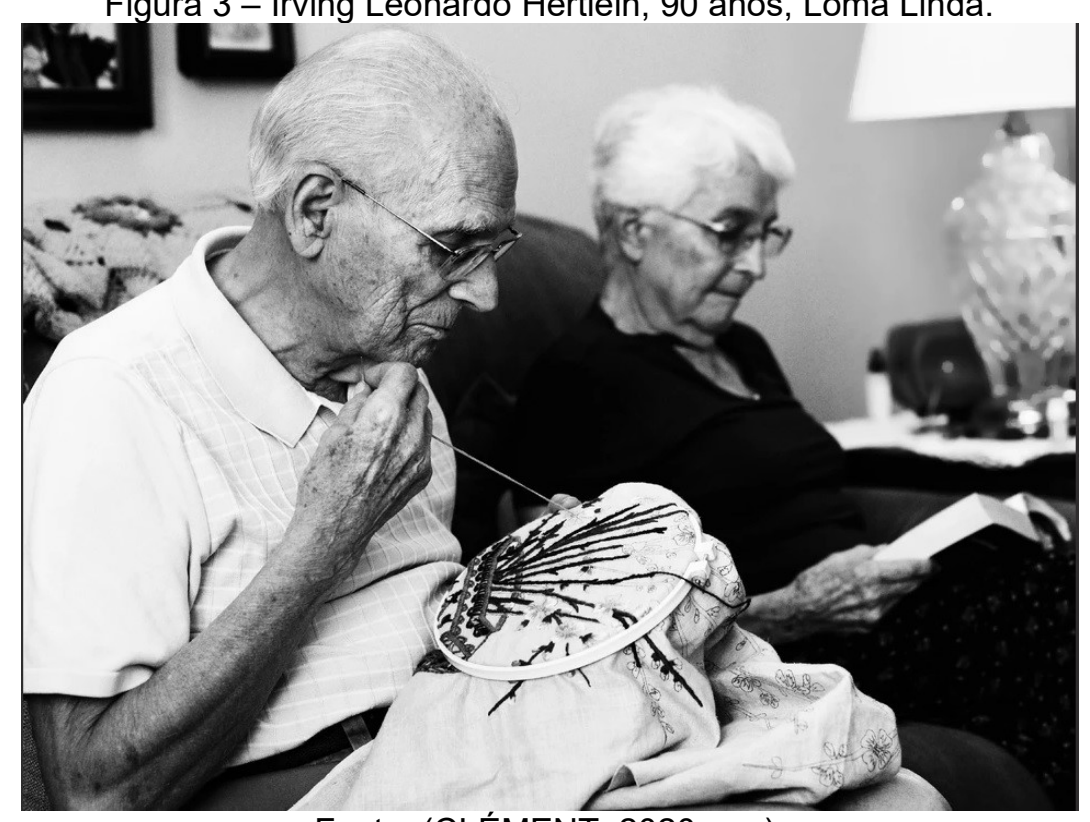

Fonte: (CLÉMENT, 2020, n.p).

Além disso, sobressai-se o fato de a canadense defender ser a luz mais importante que a cor para o trabalho fotográfico (BELTRAMELLI, 2020, n.p), portanto, entram em conflito a pletora de recurso dos equipamentos fotográficos mais avançados, que trazem consigo a promessa de um quase toque na realidade representada, de um lado, e a tentativa de captar um evento de maneira mais genuína, isto é, sem poluir o ato da captura em si com o apelo ao retoque e à edição e reedição da imagem.

A busca por esse estado de coisas aparentemente inédito desvendaria a própria aventura de um artista que queira se diferenciar dos demais tanto pela perspectiva selecionada para captar as coisas do mundo quanto pela vontade pessoal de, captandoas, sentir que empreendeu um trabalho digno de ser resgatado porque é um trabalho de atiçador de memórias.

A esse propósito, ainda é o filósofo checo-brasileiro quem provoca a força do tema quando ressalta uma possível superioridade das fotografias em preto e branco dizendo que estas "incorporam a mágica do pensamento teórico a partir do momento em que transformam o discurso linear da teoria em superfícies"7 (FLUSSER, 2006, p. 43, tradução

6 "[...] photographers wish to produce states of things that have never existed before". (FLUSSER, 2006, p. $37)$.

7 "[...] embody the magic of theoretical thought since they transform the linear discourse of theory into surfaces" (FLUSSER, 2006, p. 43). 
minha), ou seja, em coisas. "Por isso, muitos fotógrafos preferem fotografias em preto e branco às coloridas porque aquelas revelam mais claramente a atual importância da fotografia, ou seja, do mundo dos conceitos". ${ }^{8}$ (FLUSSER, 2006, p. 43, tradução minha).

Quando Clément opta por fotografar idosos em preto e branco esse ato explicita também a tentativa de um retorno às origens dessa arte em específico, pois as primeiras fotografias, tendo em vista os recursos disponíveis à época, a segunda metade do século XIX, eram em preto e branco.

Flusser (2006) alimenta a questão ao comparar fotografias coloridas com as em preto e branco, esclarecendo que aquelas contêm um maior nível de abstração e estas, ao seu turno, "[...] são mais concretas e, nesse sentido, mais verdadeiras"9 (FLUSSER, 2006, p. 43, tradução minha). Leia-se o mais verdadeiras como significando mais próximas da realidade que tentam traduzir.

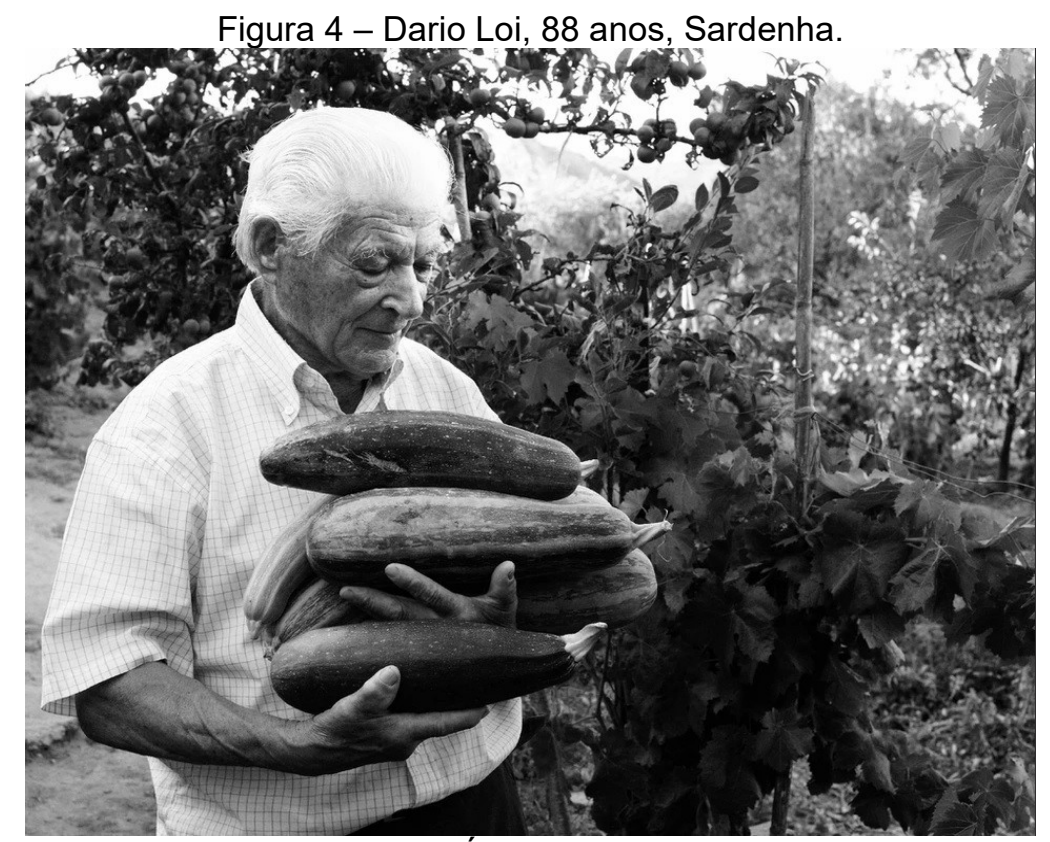

Fonte: (CLÉMENT, 2020, n.p).

Dessa perspectiva, as cores desrealizariam a realidade contida na imagem capturada, atribuindo ao objeto, a fotografia, uma falsidade que se acomoda justamente na qualidade das cores que são utilizadas para apresentar o evento que está sendo enfocado, ou seja, o excesso de artificialidade se relaciona com a alta genuinidade das cores, criptografando, em vez de decodificar, o sentido das coisas e seres representados.

Além da exploração da dimensão erótica, da beleza e do sentir-se bem, Clément também fotografa idosos imersos em suas atividades cotidianas para evidenciar que a velhice não os privou de se manterem ativos na prática dos compromissos diários (figuras 3 e 4 , primeiro projeto).

\footnotetext{
8 "Many photographers therefore also prefer black-and-white photographs to colour photographs because they more clearly reveal the actual significance of the photograph, i.e. the world of concepts." (FLUSSER, 2006, p. 43).

9 "[...] are more concrete and in this sense more true". (FLUSSER, 2006, p. 43).
} 
Sobre a primeira questão, Marie-Berthe Paquette (figura 2, do segundo projeto) é categórica, na entrevista concedida, ao afirmar que sempre teve muito cuidado com sua aparência e, assim como outras fotografadas no mesmo projeto, não somente se sente bela e atraente na idade em que se encontra como procura se cuidar para conservar um visual elegante realçado pelo uso de acessórios, um olhar exalando a beleza de estar viva, um sorriso que confirme tudo isso.

Paquette, segundo Clément (BELTRAMELLI, 2020, n.p), ensinou-lhe que alguém tem todo o direito de poder se sentir sensual mesmo aos 102 anos. "Sem hesitação, ela aceitou posar de lingerie"10 (BELTRAMELLI, 2020, n.p, tradução minha) e após mais de duas horas de sessão ela não se sentia nem um pouco cansada.

Sobre o segundo ponto, tanto Dario Loi quanto Irving Hertlein comentam cultivarem hábitos alimentares que não prejudiquem a saúde. O último se tornou vegano juntamente com a esposa após ter se tratado de um câncer na próstata. O primeiro diz que o segredo de uma vida longa está no vinho, além de consumir água e queijo (CLÉMENT, 2020, n.p).

Ambos ainda eram casados no momento do registro, e enquanto Dario confessa que sua vida sexual não mudou em nada, Irving é mais reservado, porém, menciona ser o bordado uma de suas paixões, e isso chega a surpreender algumas pessoas que o conhecem. Algo interessante nos dois se manifesta no fato de contrariarem alguns tabus sobre a velhice, como a questão sexual, também expondo de modo bastante lúcido o que pensam da situação política e econômica de seus países, bem como o que esperam para o futuro.

Por essas e outras opiniões expostas pelos fotografados, nota-se como o entendimento dos participantes dos projetos se afasta de uma visão pessimista dessa etapa da vida, igualada a um atender a morte que bate à porta e que, distante de criar fantasias a seu respeito, compreende que há limitações e cada um está consciente disso, fazendose saber que a velhice é sim apenas mais uma fase da vida de todo ser vivente, a qual não precisa ser temida ou lamentada, mas abraçada e, evidentemente, vivida.

Somado a isso, Clément reflete que "[...] [em] uma sociedade que associa a beleza com a juvente, há um penetrante medo que acompanha a ideia de envelhecer. Os últimos tabus restantes da sociedade são a nudez e a sexualidade das pessoas mais velhas." 11 (BELTRAMELLI, 2020, n.p, tradução minha).

Um e outro se mostram completos anacronismos quando se avalia como as mídias exploram uma série de outras situações da vida em sociedade e atiçam pessoas interessadas em serem o foco do momento a exporem seus corpos e suas privacidades sem qualquer constrangimento diante de câmeras que prometem aos curiosos consumidores dessas intimidades não deixar escapar nada.

Se fotografar é traduzir realidades para a condição de um objeto, como quer Flusser

\footnotetext{
10 "Without hesitation, she accepted to pose in her lingerie". (BELTRAMELLI, 2020, n.p).

11 "[...] a society that associates beauty with youth, there's a pervasive fear that comes with the idea of ageing. Society's last remaining taboos are nudity and older people's sexuality." (BELTRAMELLI, 2020, n.p).
} 
(2006), ou "[...] democratizar todas as experiências traduzindo-as em imagens"12 (SONTAG, 2005 , p. 5, tradução minha), de acordo com o pensamento de Sontag (2005), crê-se que as fotografias de Clément cumprem essas aspirações e ainda são capazes, percebe-se, de provocar a imaginação e decodificar para o espectador, através do objeto à mão, apreciado enquanto é manipulado diante dos olhos, alguns outros detalhes e informações que não estão contidos na imagem em si porque fizeram parte do momento, daquela espera na qual tomaram parte fotógrafo e fotografados.

Portanto, concebe-se que esses atos de tradução e democratização, seguindo Flusser (2006), efetuados no gesto de fotografar estão interessados mesmo não em mudar o mundo, mas em buscar nele informação e extraí-la para ser armazenada no produto resultante dessa atividade, afinal, declara Sontag (2005, p. 7, tradução minha), "[...] [a] fotografia se tornou um dos principais dispositivos para se experienciar algo, ao dar a aparência de participação"13 em um dado evento aos sujeitos envolvidos no ato da captura.

Dessa forma, supõe-se haver no trabalho de Clément uma sensibilidade que escapa dos lugares-comuns da fotografia porque não esgota o seu exercício artístico na excessiva exploração da pose como recurso técnico nem desgasta o olhar do espectador preenchendo a imagem final com detalhes ou ornamentos que poderiam ser responsáveis pela fuga do olhar, afastando-o do objeto eleito para ser capturado, armazenado no equipamento, convertido para o formato de produto no mundo que representa um eventorecorte deste e eternizado na memória para ser resgatado e tentar provocar o próprio resgate de todas as sensações em foco no momento em que o tempo parou ao soar do clique.

Se levados esses quesitos em conta, não resta dúvida de que Arianne Clément deve ser dignamente reconhecida como fotógrafa dos idosos, conforme quer sê-lo, mas, para além disso, a artista canadense, retomando-se Sontag (2005), está realmente comprometida com aquele elemento-chave inspirador da atividade de fotografar, qual seja, a busca por algo que possa ser considerado belo, e o belo, no caso em questão, se evidencia nas faces daqueles que, longe de desafiarem a passagem do tempo ou lamentarem o fato de que ele segue, sentem-se agraciados pela trajetória de existência que tiveram e olham para o futuro sem temor, cientes de que envelheceram e podem sorrir para a vida.

\section{Considerações finais}

Em preto e branco, assim Arianne Clément captura a velhice nas fotografias produzidas ao longo de viagens por todos os continentes. $E$ a opção por esse recurso, ela mesma o denuncia, está na consideração de que luz e não cor seria o mais importante para o trabalho fotográfico.

\footnotetext{
12 "[...] to democratize all experiences by translating the into images." (SONTAG, 2005, p. 5).

13 "[...] [the] photography has become one of the principal devices for experiencing something, for giving an appearance of participation." (SONTAG, 2005, p. 7).
} 
Se o Narciso de Caetano foge dos objetos que não refletem a sua imagem a contento, deve-se supor que, hoje envelhecido, ele não queira mais se fitar, afinal, caminha na esteira das opiniões comuns que reduzem a beleza a apenas uma fase da vida: a juventude.

No entanto, caso esse seja um Narciso consciente do fato de que envelheceu/rá, certamente defendeu ou há de defender posicionamento na contramão dessas imposições sociais a favor de uma juventude prolongada e que a todo custo, no sentido de valor a ser pago mesmo, não quer envelhecer porque a velhice é o fim, é a decadência, é o momento das lamentações e da morte que espreita em cada canto.

Para os idosos fotografados por Clément, como as centenárias do primeiro projeto, preocupações com a beleza não cessam porque envelheceram. Elas nutrem sim cuidado e amor por si mesmas, respeito e compreensão por seus "[...] corpos inexoravelmente marcados pela passagem do tempo"14 (BELTRAMELLI, 2020, n.p, tradução minha), e isso não lhes é motivo de sofrimento, é razão para comemorar, em todos os sentidos que o verbo comporta.

Passar pela vida em brancas nuvens, como que querendo apagar o que se viveu, não sofrer, não amar, não sentir, não chorar, já sentenciava Francisco Otaviano (ABL, 2020, n.p) em Ilusões da vida ${ }^{15}$, é não ter absolutamente vivido, é ter sido espectro e ser sombra, poeira varrida pelo vento, fumaça levada para lugar desconhecido. Esse sentimento de negação é algo que não se percebe residir nas faces serenas e sorridentes que preenchem as fotografias de Clément.

Se a velhice não ocupa lugar de destaque na contemporaneidade, porque é frequentemente ofuscada por images que pretendem fazer a beleza de refém da juventude, e aquela somente toma as notícias em momentos como o atual, no qual desponta na condição de qualificativo de um grupo de indivíduos confinados pelo risco de perecimento, isso é resultado de uma cultura que ainda associa os idosos à imagem do fim da vida, do lamento e os quer furtar das oportunidades em que poderiam expressar o que sentem, compartilhar experiências, ensinar pelas lições aprendidas ao longo de suas trajetórias.

Nesse aspecto, o mérito dos projetos de Arianne Clément é trazer para o centro, para o holofote, pessoas que, longe de se perceberem derrotadas pelo tempo, compreendemno como um aliado ao qual cabe respeito e que pela sua generosa mão lhes permitiu alcançarem um momento da existência capaz de revelar que um dos sentidos da vida pode ser justamente envelhecer, mas envelhecer amando, desejando, trabalhando, para demonstrar que não há idades melhores ou piores na vida, há etapas a serem transpostas, há histórias a serem escritas, histórias que as fotografias de Clément tornaram memoráveis.

\footnotetext{
14 "[...] body inexorably marked by the passing of time." (BELTRAMELLI, 2020, n.p).

15 Segue o poema completo: "Quem passou pela vida em branca nuvem, / E em plácido repouso adormeceu; / Quem não sentiu o frio da desgraça, / Quem passou pela vida e não sofreu; / Foi espectro de homem, não foi homem, / Só passou pela vida, não viveu."
} 


\section{Referências}

ABL. Francisco Otaviano - ilusões da vida. Disponível em: https://www.academia.org.br/academicos/francisco-otaviano/textos-escolhidos. Acesso em: 29 out. 2020.

BELTRAMELLI, Estella. Sexy at 100, Arianne Clément's photographs shine a light on sensuality in old age. Lifegate, 15 jan. 2020. Disponível em: https://www.lifegate.com/arianne-clement-photography-sexualty-old-age. Acesso em: 29 out. 2020.

BUETTNER, Dan. Blue Zones. Disponível em: https://www.bluezones.com/dan-buettner/. Acesso em: 27 out. 2020.

CLÉMENT, Arianne. Photography of the Elderly. Disponível em: https://en.arianneclement.com/. Acesso em: 27 out. 2020.

ELEGY. Direção: Isabel Coixet. Produção de Lakeshore Entertainment. Estados Unidos: Samuel Goldwyn Films, 2008. 1 DVD.

FLUSSER, Vilém. Towards a Philosophy of Photography. London, UK: Reaktion Books, 2006.

SONTAG, Susan. On Photography. New York: RosettaBooks, 2005.

WORLD HEALTH ORGANIZATION. Coronavirus disease 2019 (COVID-19). Situation Report - 51, 11 March 2020. Disponível em: https://www.who.int/docs/defaultsource/coronaviruse/situation-reports/20200311-sitrep-51-COVID-19.pdf. Acesso em: 27 out. 2020.

\section{Créditos das Imagens}

Figura 1 - Figura 1 - Anne-Marie Pronovost, 100 anos, Sutton, 2016.

Figura 2 - Figura 2 - Marie-Berthe Paquette, 102 anos, Montreal, 2016.

Figura 3 - Figura 3 - Irving Leonardo Hertlein, 90 anos, Loma Linda.

Figura 4 - Figura 4 - Dario Loi, 88 anos, Sardenha.

CLÉMENT, Arianne. Photography of the Elderly. Disponível em: https://en.arianneclement.com/. Acesso em: 27 out. 2020.

\section{NOTAS DE AUTORIA}

Victor André Pinheiro Cantuário (ve.cantuario@gmail.com) é doutorando em Estudos Literários pela Universidade Estadual de São Paulo (UNESP). Mestre em Planejamento e Políticas Públicas (2019) pela Universidade Estadual do Ceará (UECE). Graduado em Filosofia (2012) pela Universidade Estadual do Amapá (UEAP). Graduado em Letras-Francês (2008) pela Universidade Federal do Amapá (UNIFAP). Professor na Universidade Federal do Amapá (UNIFAP).

\section{Agradecimentos}

Não se aplica. 


\section{Como citar esse artigo de acordo com as normas da ABNT}

CANTUÁRIO, Victor André Pinheiro. Capturando os anos: a representação da velhice nos projetos de Arianne Clément. Anuário de Literatura, Florianópolis, v. 26, p. 01-12, 2021.

\section{Contribuição de autoria}

Não se aplica.

\section{Financiamento}

Não se aplica

\section{Consentimento de uso de imagem}

Autorização concedida pela fotógrafa Arianne Clément para publicação na Anuário de Literarua das imagens que integram o artigo.

\section{Aprovação de comitê de ética em pesquisa}

Não se aplica.

\section{Conflito de interesses}

Não se aplica.

\section{Licença de uso}

Os/as autores/as cedem à Revista Anuário de Literatura os direitos exclusivos de primeira publicação, com o trabalho simultaneamente licenciado sob a Licença Creative Commons Attribution (CC BY) 4.0 International. Estra licença permite que terceiros remixem, adaptem e criem a partir do trabalho publicado, atribuindo 0 devido crédito de autoria e publicação inicial neste periódico. Os autores têm autorização para assumir contratos adicionais separadamente, para distribuição não exclusiva da versão do trabalho publicada neste periódico (ex.: publicar em repositório institucional, em site pessoal, publicar uma tradução, ou como capítulo de livro), com reconhecimento de autoria e publicação inicial neste periódico.

\section{Publisher}

Universidade Federal de Santa Catarina. Programa de Pós-graduação em Literatura. Publicação no Portal de Periódicos UFSC. As ideias expressadas neste artigo são de responsabilidade de seus/suas autores/as, não representando, necessariamente, a opinião dos/as editores/as ou da universidade.

\section{Histórico}

Recebido em: 30/10/2021

Aprovado em: 04/05/2021

Publicado em: 31/08/2021 